\title{
Thermal Properties of the Blends of Methyl and Ethyl Esters Prepared from Babassu and Soybean Oils
}

\author{
Cleber L. Nicolau, ${ }^{a}$ Aline N. V. Klein, ${ }^{a}$ Cinthia A. A. Silva, ${ }^{a}$ Antonio R. Fiorucci, ${ }^{a}$ Jusinei M. Stropa, ${ }^{b}$ \\ Elisandra O. Santos, ${ }^{a}$ Kênia C. S. Borges, ${ }^{c}$ Rogério C. L. da Silva, ${ }^{a}$ Lincoln C. S. de Oliveira, ${ }^{b}$ \\ Edésio L. Simionatto, ${ }^{d}$ Dilamara R. Scharf ${ }^{d}$ and Euclésio Simionatto ${ }^{*, a}$ \\ aPrograma de Pós-Graduação em Recursos Naturais, \\ Universidade Estadual de Mato Grosso do Sul, 79950-000 Navirai-MS, Brazil \\ ${ }^{b}$ Instituto de Química, Universidade Federal de Mato Grosso do Sul, \\ 79070-900 Campo Grande-MS, Brazil
}

${ }^{c}$ Curso de Engenharia de Alimentos, Universidade Estadual de Mato Grosso do Sul, 79950-000 Naviraí-MS, Brazil

${ }^{d}$ Departamento de Química, Universidade Regional de Blumenau, 89012-900 Blumenau-SC, Brazil

\begin{abstract}
Fatty acid esters (methyl and ethyl) prepared from babassu nut oil were blended with the respective esters from soybean oil. These binary blends (babassu:soybean) were made in proportions of 10:90, 20:80, 30:70, 40:60, and 50:50 (vol\%). The ester content of all the blends was higher than $96.5 \%$, which is the minimum value required by the Brazilian National Agency of Petroleum, Natural Gas and Biofuels (Agência Nacional do Petróleo, Gás Natural e Biocombustíveis, ANP). The thermal properties of the babassu, soybean and binary mixtures of esters were investigated by thermogravimetry-differential thermogravimetry (TG/DTG) and differential scanning calorimetry (DSC). The thermal stability of the blended biodiesels decreased as the total contents of the babassu esters increased. From the experiments it was found that babassu methanol biodiesel is stable up to $49.6{ }^{\circ} \mathrm{C}$ and the ethanol biodiesel is stable up to $53.7^{\circ} \mathrm{C}$ in air. The methyl esters blends were thermally stable up to 83.2 and $56.8^{\circ} \mathrm{C}$, for $90: 10$ and 50:50 blends (soybean:babassu), respectively. The ethyl ester blends presented values of temperature ranges somewhat higher than the methyl esters, such as 85.2 and $64.5^{\circ} \mathrm{C}$ for $90: 10$ and 50:50 blends, respectively. The esters from babassu oil have satisfactory performance at low temperatures with respect to the point of crystallization, which were below $-9.8^{\circ} \mathrm{C}$ for ethylic esters and $-8.5^{\circ} \mathrm{C}$ for methylic esters. A good correlation between the crystallization onset temperature and the increase in the concentration of the babassu oil esters was obtained in the mixtures analyses. In the 50:50 combination (babassu:soybean), the crystallization onset temperature were -6.73 and $-9.12{ }^{\circ} \mathrm{C}$ for methyl and ethyl esters, respectively.
\end{abstract}

Keywords: babassu, biodiesel, blends, TG/DTG, DSC

\section{Introduction}

The use of edible vegetable oils for the production of biodiesel has generated great questions because they compete in agriculture with food crops. ${ }^{1,2}$ Many studies have reported that the use of non-edible oils may contribute to reduce biodiesel production issues related to the use of edible vegetable oils. ${ }^{3}$ In the Brazilian territory, there is a great variety of oleaginous crops that can be used in the production of biodiesel, but currently, most of the manufacturing processes use soybean oil as the main raw material. ${ }^{4,5}$

*e-mail: eusimionatto@yahoo.com.br
One of these oleaginous is the species Orbygnia sp. (babassu), from which a high oil content can be obtained by the processes of seed extraction. ${ }^{6,7}$ The babassu oil is considered inedible because of its high concentration of saturated fat. ${ }^{1}$

Saturated and unsaturated fatty acid alkyl esters are the main components of biodiesel. When the temperature is decreased, the compounds of saturated fraction of esters present in the composition of biodiesel can precipitate because of their higher melting temperature, and as the temperature decreased continuously, the crystal precipitation of biodiesel increases, and finally forms a network structure which causes the solidification of 
biodiesel. At present, many alternatives are used to improve this problem of biodiesel, including addition of cold flow improvers, blending with petrodiesel, fractionating by crystallization and blending of biodiesels with different compositions. $^{8-10}$

Important properties of the pure esters and blends can be evaluated by thermoanalytical techniques, such as thermogravimetric analysis (TGA), differential thermogravimetric analysis (DTG) and differential scanning calorimetry (DSC), under different atmospheres. ${ }^{11-13}$

When the TGA/DTG analysis is carried out in an oxidative atmosphere (mixture of air or oxygen and inert gas) with a linear temperature ramp, the maximum temperature is selected by where the sample weight is stable at the end of the experiment, implying that all chemical reactions have been completed. The onset temperatures can be used to indicate the resistance of the oil to thermal degradation. ${ }^{14}$

The DSC technique can be used to monitor the energy released or absorbed during the heating/cooling process. This technique has been used to determine the low temperature properties of biodiesel, as for example the onset temperature crystallization. ${ }^{8,15}$

In the present work, methyl and ethyl esters from seed oil of babassu were synthesized and their thermo-oxidative stabilities were investigated using TGA and DTG, under synthetic air atmosphere at $10{ }^{\circ} \mathrm{C} \mathrm{min}^{-1}$ heat rate. In addition, blends of esters from babassu and soybean oils were prepared and their low temperature properties were investigated by DSC. For this study, samples of nuts of babassu collected from plants found in the state of Mato Grosso do Sul, Central-West region, Brazil, were used. Considering that the babassu/soybean ester blend can contribute to the diversification of the biofuel supply patterns, important aspects related to thermal properties such as stability and crystallization point are reported here.

\section{Experimental}

\section{Materials and reagents}

Analytical grade $n$-hexane, $\mathrm{KOH}, \mathrm{Na}_{2} \mathrm{SO}_{4}$, methanol P.A. and anhydrous ethanol were obtained from a commercial source (Vetec) and used as received without any further drying or purification. The soybean oil was obtained commercially (Sadia).

\section{Collection of nuts}

Mature fruits of Orbignya sp. (babassu) were collected from trees in the municipality of Mundo Novo-MS, Brazil.
At the time of collection, the nuts were separated from the fruits and packed in vials, and stored under refrigeration. The botanical identification was performed by Prof Dr Etenaldo Felipe Santiago at the Universidade Estadual de Mato Grosso do Sul.

\section{Oil extraction}

The samples of babassu kernels were crushed in a blender and submitted to extraction with hexane for $8 \mathrm{~h}$ in Soxhlet. At the end of the extraction, the solvent was removed in rotary evaporator at $50^{\circ} \mathrm{C}$. This procedure was performed several times until approximately $2 \mathrm{~L}$ of oil was obtained. After the extraction, the oil was subjected to the degumming process according to the literature ${ }^{16}$ The oil was dried with anhydrous sodium sulfate prior to esters production.

\section{Esters samples synthesis}

The methyl and ethylic biodiesel from babassu and soybean oils were obtained by means of the transesterification reaction, using 1:6 oil:ethanol/methanol molar ratio and potassium hydroxide (1\% mass ratio) as a homogeneous basic catalyst. ${ }^{17}$ Initially, potassium ethoxide/methoxide was prepared by mixing ethanol/ methanol with $1 \mathrm{~g}$ of $\mathrm{KOH}$ for each $100 \mathrm{~g}$ of oil in a beaker, under stirring, until the complete dissolution of KOH. Next, potassium ethoxide/methoxide was added to babassu/soybean seed oil, placing the beaker on a plate featuring magnetic stirring for the transesterification reaction to occur at room temperature $\left(28^{\circ} \mathrm{C}\right)$. The time for transesterification reaction was $60 \mathrm{~min}$ for methanol and $80 \mathrm{~min}$ for ethanol. After the separation of ester and glycerin phases, the biodiesel was washed with distilled water and dried with anhydrous $\mathrm{Na}_{2} \mathrm{SO}_{4}$. The esters were analyzed by thin layer chromatography (TLC) with silica gel using as eluent hexane:ethyl acetate (85:15). The spots on the TLC plates were revealed with a solution of $10 \%$ $\mathrm{H}_{2} \mathrm{SO}_{4}$ in ethanol. Under these conditions, the esters and triglycerides present retention factors (Rf) of 0.8 and 0.5 , respectively. The reaction yield was calculated by the formula: $\operatorname{yield}(\%)=($ mass of biodiesel $/$ oil mass $) \times 100 .{ }^{18}$

\section{Preparation of blends}

The measured volumes of methyl and ethyl esters were blended with other methyl and ethyl esters with continuous stirring $\left(28{ }^{\circ} \mathrm{C}\right.$, ambient temperature) to ensure homogeneity. Methyl and ethyl esters obtained from babassu oil were blended with the same esters 
obtained from soybean oil. For each esters set (ethylic and methylic), the 10:90, 20:80, 30:70, 40:60, and 50:50 (vol\%) blends (babassu:soybean) were prepared. Samples were refrigerated until needed. Equilibration to room temperature and agitation preceded removal of sample aliquots for analysis. ${ }^{9}$

\section{Gas chromatography-mass spectrometry (GC-MS) analysis}

The GC-MS analysis for the identification of fatty acid methyl and ethyl esters was conducted using a Shimadzu GCMS-QP2010 Plus gas chromatograph. The samples of esters were $(1 \mu \mathrm{L})$ through a Shimadzu auto sampler AOC-20s + i into the Stabilwax column (30 m length, $0.25 \mathrm{~mm}$ i.d., $0.25 \mu \mathrm{m}$ film thickness). The oven temperature was programmed from $60{ }^{\circ} \mathrm{C}(2 \mathrm{~min})$ and then increased at $10{ }^{\circ} \mathrm{C} \mathrm{min}^{-1}$ up to $200{ }^{\circ} \mathrm{C}(10 \mathrm{~min})$, and increased at $5{ }^{\circ} \mathrm{C} \mathrm{min}^{-1}$ up to $240{ }^{\circ} \mathrm{C}(15 \mathrm{~min})$. The injector temperature was $250{ }^{\circ} \mathrm{C}$. Helium was the carrier gas with a flow rate of $1.5 \mathrm{~mL} \mathrm{~min}^{-1}$ and 1:50 was the split ratio. The MS scan parameters included a mass range of $40-650 \mathrm{~m} / \mathrm{z}$. The temperatures of ion source and interface were 250 and $255^{\circ} \mathrm{C}$, respectively. For the identification of mass spectra, NIST08 library and NIST analysis program software were used. GC-MS solution integrated software (Shimadzu Cat. No. 225-16584-92) was also used for the chromatogram analysis.

\section{GC with flame ionization detector (GC-FID) analysis}

Gas chromatograph (Shimadzu GC 2010) was used to analyze the fatty acid composition of the produced biodiesel. The retention times of esters of the sample were compared to those of the standard fatty acid methyl esters (FAME). Quantity of each component was calculated from the relative peak area and considered as a percentage by mass. The ester content in the sample of biodiesel was determined according to the EN14103 method, ${ }^{19}$ using methyl heptadecanoate as an internal standard.

\section{TGA}

An analyzer model TGA Q-50 (TA Instruments) was employed for TGA/DTG test of pure esters and blends. The amounts of samples used were $10 \mathrm{mg}$. The analysis was performed with heating rate of $10{ }^{\circ} \mathrm{C} \mathrm{min}{ }^{-1}$ from room temperature to $700^{\circ} \mathrm{C}$, under synthetic air atmosphere, with a purge flow of $60 \mathrm{~mL} \mathrm{~min}{ }^{-1}$ in the oven and $40 \mathrm{~mL} \mathrm{~min}^{-1}$ in the balance, using platinum crucible for support. Onset temperature was also used to indicate the thermal resistance of the esters. ${ }^{20,21}$
DSC

The DSC curves were obtained in a calorimeter model DSC Q20 with the RCS90 coupled to a cooling system, both from TA Instruments. For such analyses, the sample masses were used ranging from $4.00-4.50 \mathrm{mg}$ using aluminum crucibles (Tzero standard) as support and reference, rate of heating/cooling of $10{ }^{\circ} \mathrm{C} \mathrm{min}^{-1}$, cycle heating followed by cooling to temperatures between -80 and $30^{\circ} \mathrm{C}$, under inert

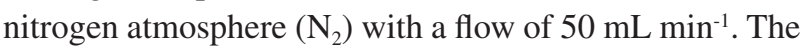
data were processed with the help of Universal Analyses 2000 software version 3.7A (TA Instruments).

\section{Results and Discussion}

\section{Chemical analysis}

The products of the transesterification reaction of the soybean and babassu oils were analyzed using gas chromatography to access the conversion of the triglycerides to methyl and ethyl esters. Table 1 shows the chemical compositions of the pure methyl and ethyl esters samples prepared with babassu and soybean oils. According to standard EN14103, ${ }^{19}$ the percentage of esters was determined in the samples, all of which had levels above the established (96.5\%), therefore, these esters mixtures have an acceptable level as biodiesel.

Table 1. Composition of fatty acid methyl and ethyl esters obtained by transesterification of the babassu and soybean oils

\begin{tabular}{|c|c|c|c|c|}
\hline \multirow[t]{2}{*}{ Fatty acid source } & \multicolumn{2}{|c|}{$\begin{array}{c}\text { Methyl ester } \\
\text { composition / \% }\end{array}$} & \multicolumn{2}{|c|}{$\begin{array}{c}\text { Ethyl ester } \\
\text { composition / \% }\end{array}$} \\
\hline & Babassu & Soybean & Babassu & Soybean \\
\hline Caproic C6:0 & 0.38 & - & 0.32 & - \\
\hline Caprilic C8:0 & 6.38 & - & 6.50 & - \\
\hline Capric C10:0 & 6.32 & - & 6.50 & - \\
\hline Lauric C12:0 & 43.80 & - & 43.54 & - \\
\hline Myristic C14:0 & 12.91 & - & 12.97 & - \\
\hline Palmitic C16:0 & 7.93 & 10.60 & 7.90 & 10.60 \\
\hline Stearic C18:0 & 3.78 & 3.90 & 3.70 & 3.91 \\
\hline Oleic C18:1 & 13.50 & 25.92 & 13.05 & 25.27 \\
\hline Linoleic C18:2 & 2.50 & 49.80 & 2.82 & 49.75 \\
\hline Linolenic C18:3 & 0.16 & 5.86 & - & 5.90 \\
\hline Arachidonic C20:0 & - & 0.61 & - & 0.42 \\
\hline Eicosenoic C20:1 & - & 0.31 & - & 0.30 \\
\hline Behenic C22:0 & - & 0.54 & - & 0.52 \\
\hline Saturated & 81.50 & 14.50 & 81.43 & 14.51 \\
\hline Unsaturated & 16.16 & 83.04 & 15.87 & 82.16 \\
\hline Total & 97.66 & 97.54 & 97.30 & 96.67 \\
\hline
\end{tabular}


It can be observed that the esters of babassu oil are mainly composed of esters derived from lauric acid (43.58-43.80\%), followed by oleic acid (13.05-13.50\%) and myristic acid (12.9\%). In contrast, the esters of soybean oil are composed of linoleic acid (49.8\%), followed by oleic acid (25.27-25.92\%) and palmitic acid (10.6\%). In general, the fatty acid contents of babassu and soybean oils obtained in this study are comparable/similar to the values obtained by other studies with these oils., ${ }^{71,22}$ In general, it can be noted that the esters obtained from babassu and soybean oils have an almost inverse profile regarding the content of saturated and unsaturated esters. Babassu esters have amounts of approximately $81.5 \%$ of saturated esters, while esters obtained from soybean oil have a content close to $14.5 \%$. As for unsaturated esters, those obtained from soybean oil have approximately $83-82 \%$, while those of babassu have $16 \%$. Babassu oil has already been mentioned in the literature as important raw material for the production of biodiesel and their physicochemical properties are suitable for this application..$^{1,10}$

From the methyl and ethyl esters previously obtained, the blends were prepared. For the preparation of the blends, increasing amounts of babassu oil esters $(10,20$, 30,40 and $50 \%$ ) were added to esters of soybean oils, obtaining the blends (babassu:soybean) 10:90, 20:80, 30:70, 40:60 and 50:50. These blends were again analyzed by gas chromatography. The compositions of these blends of the methyl and ethyl esters are shown in Tables 2 and 3, respectively. It can be seen that according to the increase in the proportion of babassu esters, blends with a higher proportion of saturated esters are obtained. In the end, blends with large differences in the content of saturated and unsaturated esters were obtained when compared to pure esters obtained from babassu and soybean oils. The major compounds of mixtures of the soybean (derived from linoleic acid) and babassu (derived from lauric acid) oil esters have an opposite behavior in accordance with the increased content of babassu oil esters. The esters derived from linoleic acid decrease their content, while esters derived from lauric acid increase their content in the blends.

\section{TG/DTG analysis of esters and blends}

Thermal analysis was performed in an oxidative atmosphere (synthetic air) with a linear temperature ramp. The maximum temperature is selected so that the sample weight is stable at the end of the experiment, indicating the end of all chemical transformations. Therefore, the oxidative stability is a quality indicative parameter for esters (biodiesel components). ${ }^{23}$
Table 2. Composition of fatty acid methyl esters obtained with the blends 10:90, 20:80, 30:70, 40:60 and 50:50 (babassu:soybean)

\begin{tabular}{lccccc}
\hline $\begin{array}{l}\text { Blend } \\
\text { (babassu:soybean) }\end{array}$ & \multicolumn{5}{c}{ Methyl ester composition / \% } \\
\cline { 2 - 6 } Caproic C6:0 & - & - & - & 0.14 & 0.21 \\
Caprilic C8:0 & 0.58 & 1.18 & 1.71 & 3.10 & 3.32 \\
Capric C10:0 & 0.58 & 1.20 & 1.76 & 3.30 & 3.52 \\
Lauric C12:0 & 3.03 & 8.21 & 12.03 & 18.81 & 23.10 \\
Myristic C14:0 & 1.28 & 2.54 & 3.68 & 6.98 & 7.10 \\
Palmitic C16:0 & 10.35 & 10.11 & 9.73 & 10.30 & 10.20 \\
Stearic C18:0 & 3.90 & 3.92 & 3.98 & 4.22 & 4.22 \\
Oleic C18:1 & 28.11 & 23.15 & 21.66 & 20.85 & 20.71 \\
Linoleic C18:2 & 45.10 & 40.90 & 36.52 & 25.86 & 22.55 \\
Linolenic C18:3 & 5.27 & 4.81 & 4.30 & 3.89 & 3.08 \\
Arachidonic C20:0 & 0.37 & 0.34 & 0.30 & 0.26 & 0.26 \\
Eicosenoic C20:1 & 0.28 & 0.25 & 0.23 & 0.21 & 0.18 \\
Behenic C22:0 & 0.48 & 0.43 & 0.36 & 0.21 & 0.10 \\
\hline Saturated & 19.72 & 27.16 & 32.89 & 46.85 & 51.67 \\
Unsaturated & 78.58 & 69.88 & 63.37 & 51.28 & 46.88 \\
\hline Total & 99.33 & 97.04 & 96.26 & 98.13 & 98.55 \\
\hline
\end{tabular}

Table 3. Composition of fatty acid ethyl esters obtained with the blends 10:90, 20:80, 30:70, 40:60 and 50:50 (babassu:soybean)

\begin{tabular}{lccccc}
\hline \multirow{2}{*}{$\begin{array}{l}\text { Blend } \\
\text { (babassu:soybean) }\end{array}$} & \multicolumn{5}{c}{ Ethyl ester composition / \% } \\
\cline { 2 - 6 } Caproic C6:0 & - & - & 0.10 & 0.12 & 0.15 \\
Caprilic C8:0 & 0.64 & 1.20 & 1.90 & 2.52 & 3.17 \\
Capric C10:0 & 0.62 & 1.23 & 1.89 & 2.53 & 3.19 \\
Lauric C12:0 & 4.10 & 8.28 & 12.68 & 16.97 & 21.40 \\
Myristic C14:0 & 1.28 & 2.54 & 3.83 & 5.50 & 6.40 \\
Palmitic C16:0 & 10.34 & 10.03 & 9.77 & 9.50 & 9.19 \\
Stearic C18:0 & 3.82 & 3.80 & 3.91 & 3.78 & 3.75 \\
Oleic C18:1 & 24.10 & 22.91 & 21.67 & 20.45 & 19.18 \\
Linoleic C18:2 & 45.20 & 40.95 & 36.17 & 31.46 & 26.53 \\
Linolenic C18:3 & 5.29 & 4.81 & 4.21 & 3.63 & 3.10 \\
Arachidonic C20:0 & 0.37 & 0.33 & 0.30 & 0.26 & 0.23 \\
Eicosenoic C20:1 & 0.27 & 0.25 & 0.22 & 0.20 & 0.18 \\
Behenic C22:0 & 0.47 & 0.41 & 0.36 & 0.31 & 0.26 \\
\hline Saturated & 20.80 & 27.08 & 34.08 & 40.92 & 47.25 \\
Unsaturated & 75.70 & 69.66 & 62.93 & 56.31 & 49.48 \\
\hline Total & 96.50 & 96.74 & 97.00 & 97.23 & 96.73 \\
\hline
\end{tabular}

TG/DTG curves of methyl and ethyl esters obtained from soybean and babassu oils showed the thermal events listed in Table 4. Figure 1 shows the thermogravimetric profile (TG/DTG) of esters obtained from babassu oil. 
For methyl esters, $10 \%$ weight loss was observed at 150.7 and $87.3{ }^{\circ} \mathrm{C}$ for soybean and babassu, respectively. With ethyl esters, the $10 \%$ weight loss was observed at 157.8 and $97.8{ }^{\circ} \mathrm{C}$ for soybean and babassu, respectively. This behavior remained similar for weight losses of 50 and $90 \%$. Methyl esters and ethyl esters from soybean oil were thermally stable up to 112.4 and $115.2{ }^{\circ} \mathrm{C}$ in synthetic air atmosphere, respectively. For esters from babassu oil, the degradation starts at 49.6 and $53.7^{\circ} \mathrm{C}$, for methyl and ethyl esters, respectively.

Table 4. Temperatures of mass loss (10,50 and 90\%) of the pure methyl and ethyl esters from soybean and babassu oils under synthetic air atmosphere

\begin{tabular}{lccc}
\hline & \multicolumn{3}{c}{ Temperature of mass loss $/{ }^{\circ} \mathrm{C}$} \\
\cline { 2 - 4 } & \multicolumn{3}{c}{ Soybean esters } \\
\cline { 2 - 4 } & $10 \%$ & $50 \%$ & $90 \%$ \\
\hline Methyl esters & 150.7 & 183.8 & 201.0 \\
Ethyl esters & 157.8 & 197.2 & 225.6 \\
\hline & \multicolumn{3}{c}{ Babassu esters } \\
\cline { 2 - 4 } & $10 \%$ & $50 \%$ & $90 \%$ \\
\hline Methyl esters & 87.3 & 133.1 & 166.9 \\
Ethyl esters & 97.8 & 144.7 & 178.8 \\
\hline
\end{tabular}

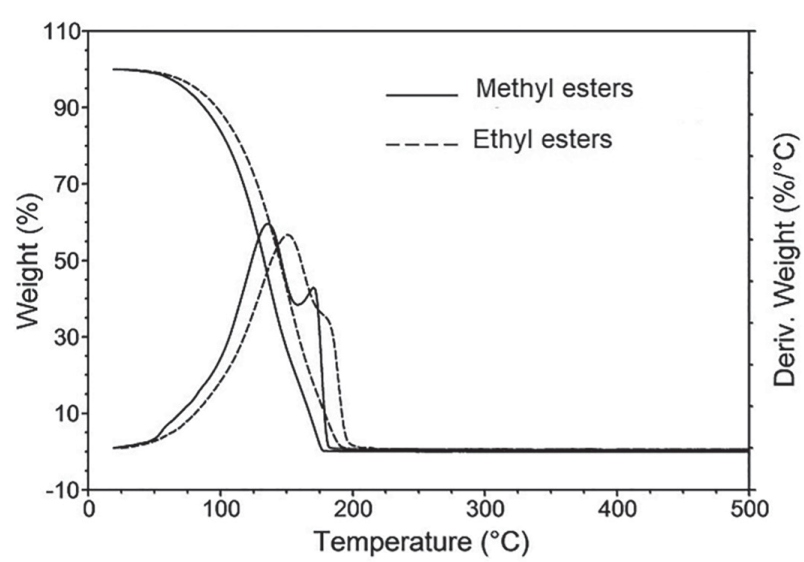

Figure 1. TG and DTG curves of methyl and ethyl esters of babassu.

In the TG/DTG curves of the ester blends (Table 5 and Figures 2 and 3) it was observed that the mass loss temperatures (10,50 and 90\%) are altered as the content of esters obtained from babassu oil is increased, and that these temperatures are lower than those obtained for the esters from soybean oil.

The onset temperatures (Ton), as shown in Table 6, can be used to indicate the resistance of the oil/esters to thermal degradation. This variable was obtained by extrapolating the horizontal baseline with a degradation of $1 \%$. By making the intercept of this line with the tangent to the descending portion of the weight curve, the point defined
Table 5. Temperatures of mass loss (10,50 and 90\%) of the esters blends (babassu:soybean) under synthetic air atmosphere

\begin{tabular}{lccc}
\hline \multirow{3}{*}{ Blend } & \multicolumn{3}{c}{ Temperature of mass loss $/{ }^{\circ} \mathrm{C}$} \\
\cline { 2 - 4 } & \multicolumn{3}{c}{ Methyl esters } \\
\cline { 2 - 4 } $10: 90$ & $10 \%$ & $50 \%$ & $90 \%$ \\
\hline $20: 80$ & 129.8 & 173.4 & 199.7 \\
$30: 70$ & 118.9 & 173.8 & 197.1 \\
$40: 60$ & 107.1 & 162.6 & 196.7 \\
$50: 50$ & 105.9 & 161.9 & 195.2 \\
\hline & & Ethyl esters \\
\hline $10: 90$ & $10 \%$ & $50 \%$ & $90 \%$ \\
$20: 80$ & 144.1 & 189.4 & 214.7 \\
$30: 70$ & 134.3 & 187.5 & 213.5 \\
$40: 60$ & 126.1 & 183.5 & 212.0 \\
$50: 50$ & 119.9 & 177.8 & 209.3 \\
\hline
\end{tabular}

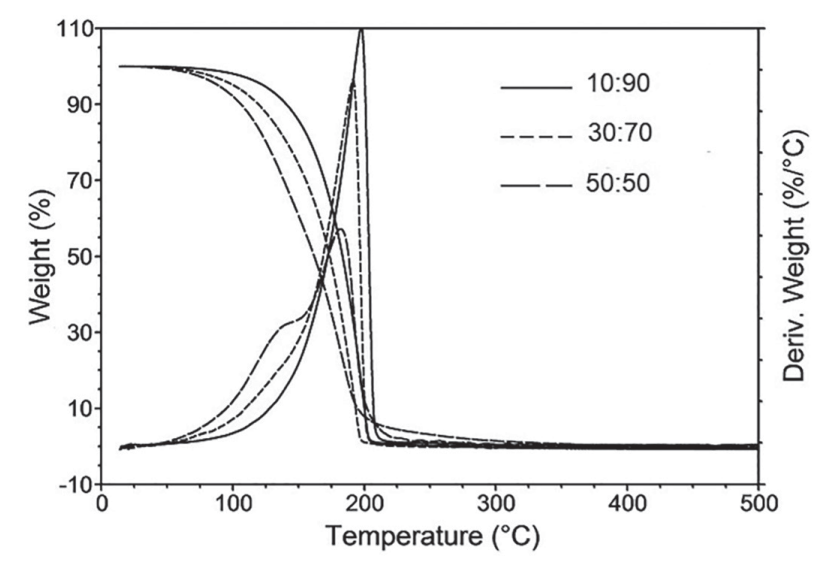

Figure 2. TG and DTG curves of babassu methyl esters blends (babassu:soybean): 10:90, 30:70 and 50:50.

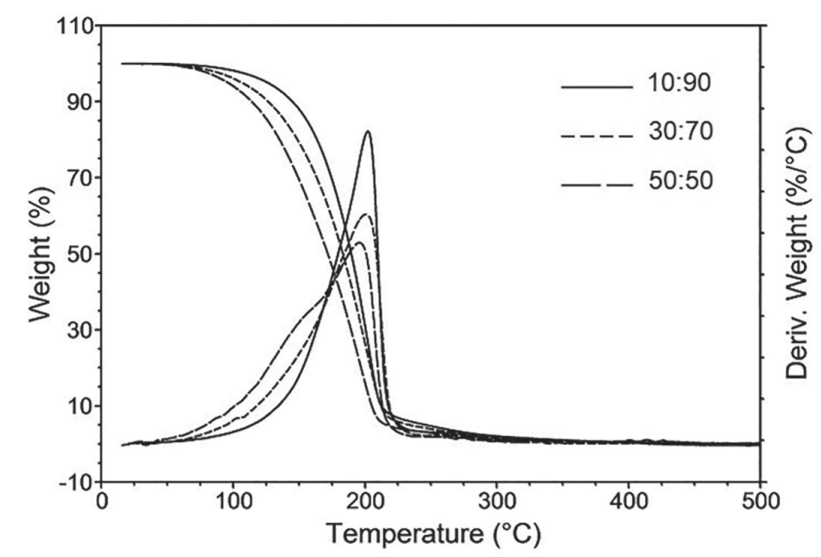

Figure 3. TG and DTG curves of babassu ethyl esters blends 10:90, 30:70 and 50:50. 
as the onset temperature is obtained. As the oil is oxidized, its onset temperature decreases. ${ }^{21}$ Then, we can state that the babassu oil esters are much less thermally resistant than the esters of soybean oils.

Table 6. Temperature onset of the pure esters (100\%) and the blends of babassu:soybean esters

\begin{tabular}{lcc}
\hline \multirow{2}{*}{ Sample } & \multicolumn{2}{c}{ Temperature onset $/{ }^{\circ} \mathrm{C}$} \\
\cline { 2 - 3 } & Methyl esters & Ethyl esters \\
\hline Soybean esters 100\% & 163.6 & 164.8 \\
Babassu esters 100\% & 100.9 & 108.5 \\
Blend 10:90 & 157.4 & 159.7 \\
Blend 20:80 & 150.2 & 154.2 \\
Blend 30:70 & 141.7 & 143.5 \\
Blend 40:60 & 112.5 & 135.2 \\
Blend 50:50 & 109.0 & 120.7 \\
\hline
\end{tabular}

It is known that the higher the onset temperature, the lower the heat of combustion. ${ }^{14}$ From the analysis of typical compositions of the studied oils, it is interesting to note that only esters from babassu oil are made up of saturated fatty acids molecules of $6,8,10,12,14$ and 16 carbon atoms (ca. 75\%) with the highest content of those with C:12 atoms (ca. 43\%), which explains its lowest decomposition onset temperature. On the other hand, esters from soybean oil consist of highest content of unsaturated fatty acid molecules with C:18 atoms (ca. 85\%), which shows the highest thermal stability among the oils. Thus, the lower molecular mass of the babassu oil esters reflects in a lower thermal stability (lower temperature onset), as compared to the soybean oil esters which have larger chain esters. This effect was observed in the blends, as the proportion of esters of babassu oil increased, the decomposition onset temperature decreased (Table 6). This observation is in agreement with the data obtained from thermal analyses of some commercial vegetable oils (canola, sunflower, corn, olive and soybean). Based on the respective decomposition onset temperatures obtained from respective TG curves in air, corn oil presents the highest thermal stability, followed in decreasing stability order by sunflower, soybean, canola and olive oils. This behavior is attributed to the presence of saturated compounds only in the composition of olive oil, especially those with chains of 14 and 16 carbons..$^{14,24}$ Considering that in esters derived from babassu oil there is a high content of compounds with smaller carbon chains than those in the soybean oil derivatives, this behavior can also be expected.

The TG/DTG curves of the blends of esters in air showed significant differences when compared to the pure esters and with the different proportions of blends. It was observed that as the proportion of babassu oil esters increased, the blend decreased its thermal stability, that is, the degradation event occurred at lower temperatures.

As shown in Figures 2 and 3, the TG/DTG curves indicate that oxidative degradation of the methyl esters blends occurred in a single continuous step in the temperature range $83.2-210$ and $56.8-200.9{ }^{\circ} \mathrm{C}$ for $90: 10$ and 50:50 blends (babassu:soybean), respectively. The ethyl ester blends presented values of temperature ranges somewhat higher than the methyl esters, such as 85.2-248 and $64.5-216^{\circ} \mathrm{C}$ for the blends 10:90 and 50:50, respectively. In these temperature ranges, the mass losses occur at levels of $95 \%$. The other blends $(20: 80,30: 70,40: 60)$ presented intermediate values, showing that the effect of decrease of the temperature ranges occurs according to the addition of proportions of babassu oil esters.

Although there is a decrease in stability with an increase in the proportion of babassu esters, the values obtained for mass loss (10,50 and 90\%) and temperature onset are comparable with data obtained for other raw materials used in the production of biodiesel..$^{15,23,25}$

DSC analysis: the crystallization behavior of esters and blends

In the present study, the crystallization temperatures of methyl esters and ethyl esters prepared from the oils of soybean and babassu were estimated by DSC, according to the literature. ${ }^{26} \mathrm{~A}$ typical ester DSC thermogram is shown in Figure 4, which demonstrates the different crystallization onset temperatures of the ethyl and methyl esters. The crystallization onset temperatures of methyl esters and ethyl esters were -2.8 and $-3.9^{\circ} \mathrm{C}$, for soybean, respectively. The babassu esters showed the crystallization onset temperatures of methyl esters and ethyl esters with values of -8.5 and $-9.8{ }^{\circ} \mathrm{C}$, respectively (Table 7).

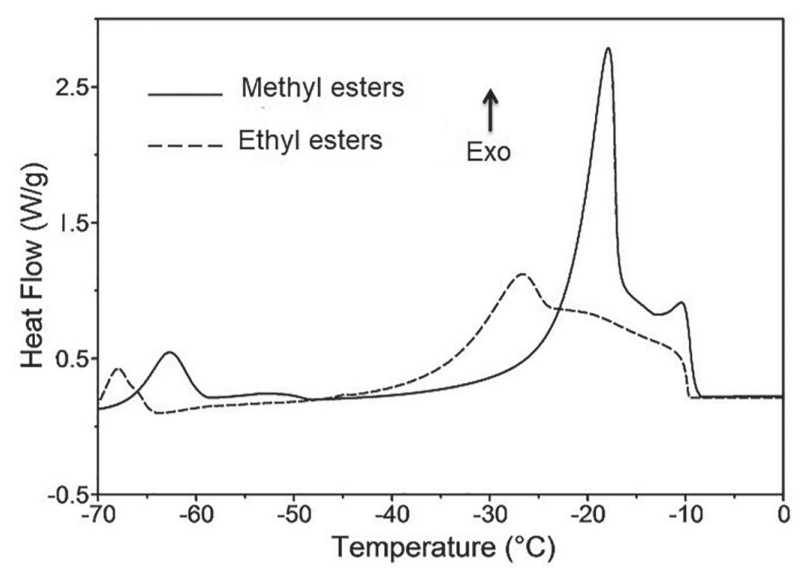

Figure 4. DSC curves of pure methyl and ethyl esters of babassu. 
Table 7. Crystallization points of methyl and ethyl esters obtained from soybean and babassu oils by DSC

\begin{tabular}{lcc}
\hline \multirow{2}{*}{ Sample } & \multicolumn{2}{c}{ Crystallization point $/{ }^{\circ} \mathrm{C}$} \\
\cline { 2 - 3 } & Soybean esters & Babassu esters \\
\hline Methyl esters & -2.8 & -8.5 \\
Ethyl esters & -3.9 & -9.8 \\
\hline
\end{tabular}

These values of crystallization temperatures had repercussions on the blends (Figures 5 and 6), where a good relationship of the increase of babassu oil ester proportions with the lowering of the crystallization temperatures of the blends was observed (Table 8).

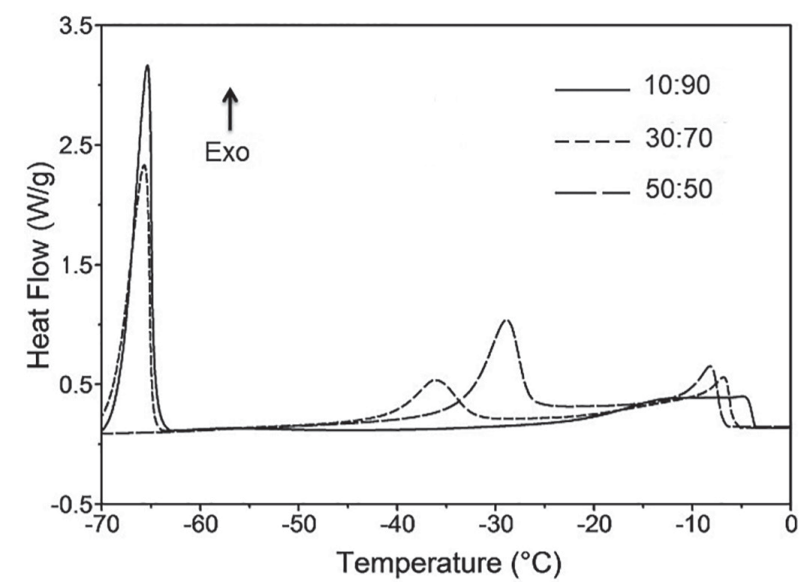

Figure 5. DSC curves of babassu methyl esters blends 10:90, 30:70 and $50: 50$.

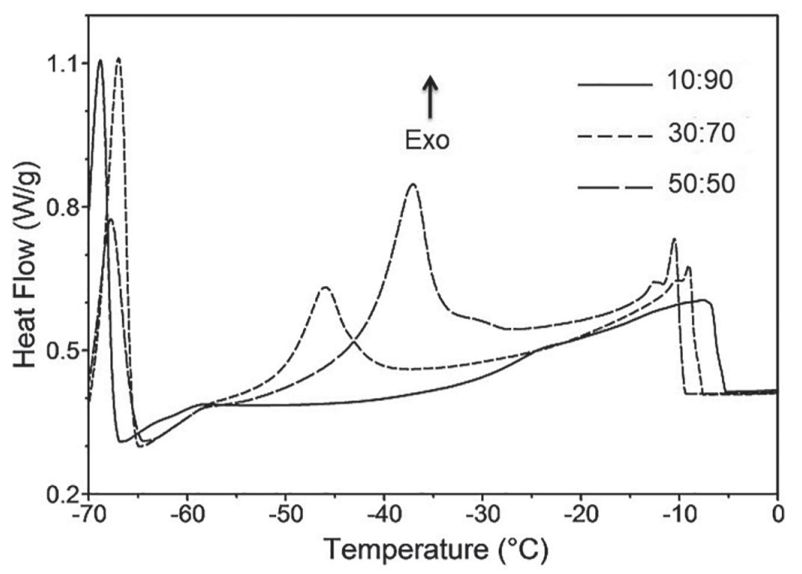

Figure 6. DSC curves of babassu ethyl esters blends 10:90, 30:70 and 50:50.

This behavior may be justified by the specific effect of some esters of fatty acids. According to literature data, ${ }^{27}$ the crystallization temperatures of the methyl esters of lauric, palmitic, stearic and oleic acids were previously determined by DSC, with temperatures of $-4.0,23.2,31.6$ and $-19.8{ }^{\circ} \mathrm{C}$, respectively. Also, in this same work, the influence of unsaturations on the crystallization temperature
Table 8. Crystallization points of the blends of methyl and ethyl esters obtained from soybean and babassu oils by DSC

\begin{tabular}{lcc}
\hline \multirow{2}{*}{$\begin{array}{l}\text { Blend } \\
\text { (babassu:soybean) }\end{array}$} & \multicolumn{2}{c}{ Crystallization point $/{ }^{\circ} \mathrm{C}$} \\
\cline { 2 - 3 } $10: 90$ & Methyl esters & Ethyl esters \\
\hline $20: 80$ & -3.80 & -5.24 \\
$30: 70$ & -4.92 & -6.32 \\
$40: 60$ & -5.25 & -7.61 \\
$50: 50$ & -6.36 & -8.04 \\
\hline
\end{tabular}

of the stearic acid ( 0 unsaturations), oleic (1 unsaturation), linoleic (2 unsaturations) and linolenic (3 unsaturations) methyl esters were investigated, obtaining the temperatures of $23.2,-19.8,-30.0$ and $-30.0^{\circ} \mathrm{C}$, respectively.

Therefore, it is noted that although they are saturated esters, the thermal behavior of the methyl esters of lauric and palmitic acids is quite dissimilar, with a great difference in the temperature at the beginning of the crystallization point of the methyl laurate esters and methyl palmitate, being these temperatures -4.0 and $23.2{ }^{\circ} \mathrm{C}$, respectively.

As noted, the major methyl and ethyl esters obtained by the transesterification of babassu oil are lauric acid derivatives (12:0). The distribution of these esters ranges from $3.0-23.1 \%$ in the blends of methyl esters and $4.0-21.4 \%$ in the blends of ethyl esters. Thus, these esters (derived from lauric acid) are probably responsible for the low temperature crystallization of these mixtures.

\section{Conclusions}

Babassu oil has the potential to contribute to the energy supply mix through its transesterification, being that routes with methanol and ethanol are easy ways that can be used to produce fuels (biodiesel). This work showed that the ethyl and methyl esters obtained from babassu oil have important thermal properties that contribute to the use as fuel. The results revealed that the esters of babassu oil have a lower thermal stability when compared to soybean oil, which is the result of their chemical composition which is formed by saturated esters of low molecular weight. The crystallization point of the babassu oil esters has very low values when compared to esters from other sources due to the high content of esters derived from lauric acid, which has this characteristic. Blend formulations of babassu and soybean oil esters have also shown that the thermal properties of babassu esters are suitable for possible use as a fuel in these forms (blends). Considering that in Brazil a large part of the biodiesel produced uses soybean oil (an edible oil) as raw material and that babassu is considered 
a non-edible oil due to its high saturated fat content, it can be proposed to use this oil as a source of this fuel in the form of blends. Another application could be the use of the esters as an additive to reduce the temperature of the crystallization point, in blends with other types of esters.

\section{Acknowledgments}

We are grateful for the financial support from FundectMS, Capes and CNPq.

\section{References}

1. Paiva, E. J. M.; da Silva, M. L. C. P.; Barbosa, J. C. S.; de Oliveira, P. C.; de Castro, H. F.; Giordani, D. S.; Ultrason. Sonochem. 2013, 20, 833.

2. Silitonga, A. S.; Hassan, M. H.; Ong, H. C.; Kusumo, F.; Mahlia, T. M. I.; Bahar, A. H.; J. Cleaner Prod. 2016, 120, 654.

3. Atabani, A. E.; Silitonga, A. S.; Ong, H. C.; Mahlia, T. M. I.; Masjuki, H. H.; Badruddin, I. A.; Fayaz, H.; Renewable Sustainable Energy Rev. 2013, 18, 211.

4. Alexandre, E. C. F.; Silveira, E. V.; de Souza Castro, C. F.; Sales, J. F.; de Oliveira, L. C. S.; Viana. L. H.; Barbosa, L. C. A.; Fuel 2015, 161, 233.

5. Silva, L. N.; Cardoso, C. C.; Pasa, V. M. D.; Fuel 2016, 166, 453.

6. Lima, J. R.; da Silva, R. B.; da Silva, L. S. S.; dos Santos, J. R.; Moura, E. M.; de Moura, C. V. R.; Quim. Nova 2007, 30, 600.

7. Teixeira, M. A.; Biomass Bioenergy 2007, 32, 857.

8. Chen, W.; Wang, Y.; Ding, M.; Shi, S.; Yang, Z.; Fuel 2017, 207, 503

9. Moser, B. R.; Renewable Energy 2016, 85, 819.

10. Serrano, M.; Oliveros, R.; Sánchez, M.; Moraschini, A.; Martín, M.; Aracil, J.; Energy 2014, 65, 109.

11. Conceição, M. M.; Candeia, R. A.; Silva, F. C.; Bezerra, A. F.; Fernandes, V. J.; Souza, A. G.; Renewable Sustainable Energy Rev. 2007, 11, 964.

12. Dantas, M. B.; Conceição, M. M.; Fernandes, V. J.; Santos, N. A.; Rosenhaim, R.; Marques, A. L. B.; J. Therm. Anal. Calorim. 2007, 87,835 .
13. Dantas, M. A.; Albuquerque, A. R.; Barros, A. K.; Rodrigues Filho, M. G.; Antoniosi Filho, N. R.; Sinfrônio, F. S. M.; Rosenhaim, R.; Soledade, L. E. B.; Santos, I. M. G.; Souza, A. G.; Fuel 2011, 90, 773.

14. Jain, S.; Sharma, M. P.; Renewable Sustainable Energy Rev. 2011, 15, 438.

15. Cabral, M. R. P.; Santos, S. A. L. D.; Stropa, J. M.; Silva, R. C. D. L. D.; Cardoso, C. A. L.; Oliveira, L. C. S. D.; Scharf, D. R.; Simionatto, E. L.; Santiago, E. F.; Simionatto, E.; Ind. Crops Prod. 2016, 85, 109.

16. Araújo, F. D. S.; Araújo, I. C.; Costa, I. C. G.; de Moura, C. V. R.; Chaves, M. H.; Araújo, E. C. E.; Renewable Energy 2014, 71, 495.

17. Pierezan, L.; Cabral, M. R. P.; Neto, D. M.; Stropa, J. M.; de Oliveira, L. C. S.; Scharf, D. R.; Simionatto, E. L.; da Silva, R. C. L.; Simionatto, E.; Quim. Nova 2015, 38, 328.

18. Takase, M.; Zhang, M.; Feng, W.; Chen, Y.; Zhao, T.; Cobbina, S. J.; Yang, L.; Wu, X.; Energy Convers. Manage. 2014, 80, 117.

19. EN 14103: Fat and Oil Derivatives - Fatty Acid Methyl Esters (FAME), Determination of Ester and Linolenic Acid Methyl Ester Content; European Committee for Standardization, Berlin, 2003.

20. Jain, S.; Sharma, M. P.; Fuel 2012, 93, 252.

21. Wan-Nik, W. B.; Ani, F. N.; Masjuki, H. H.; Energy Convers. Manage. 2005, 46, 2198.

22. Da Rós, P. C. M.; Silva, W. C.; Grabauskas, D.; Perez, V. H.; de Castro, H. F.; Ind. Crops Prod. 2014, 52, 313.

23. Borugadda, V. B.; Goud, V. V.; Thermochim. Acta 2014, 577, 33.

24. Dweck, J.; Sampaio, C. M. S.; J. Therm. Anal. Calorim. 2004, 75,385 .

25. Silva, T. A.; de Assunção, R. M. N.; Vieira, A. T.; de Oliveira, M. F.; Batista, A. C. F.; Fuel 2014, 136, 10.

26. Lin, R.; Zhu, Y.; Tavlarides, L. L.; Fuel 2014, 117, 981.

27. Rodrigues Jr., J. A.; Cardoso, F. P.; Lachter, E. R.; Estevão, L. R. M.; Lima, E.; Nascimento, R. S. V.; J. Am. Oil Chem. Soc. 2006, 83, 353.

Submitted: September 18, 2017 Published online: March 7, 2018 